Encontros Bibli: revista eletrônica de biblioteconomia e ciência da informação, $v .17, n$. esp. 2 - III SBCC, p.174-194, 2012. ISSN 1518-2924. DOI: 10.5007/15182924.2012v17nesp2p174

\title{
O PAPEL DAS BIBLIOTECAS UNIVERSITÁRIAS NA COMUNICAÇÃO CIENTÍFICA: UM ESTUDO SOBRE OS REPOSITÓRIOS INSTITUCIONAIS
}

\author{
Patrícia dos Santos Caldas Marra ${ }^{\mathrm{i}}$
}

\begin{abstract}
Resumo: Trata-se de um trabalho de revisão de literatura, seguida de uma pesquisa realizada por meio de questionário estruturado com perguntas abertas e fechadas, com o objetivo de obter informações sobre o panorama de implantação de repositórios institucionais de acesso livre à informação científica pelas universidades do Brasil. A pesquisa foi dividida em três etapas: análise dos sites institucionais das 102 IES identificadas pelo sistema e-MEC visando localização do e-mail para contato das bibliotecas; aplicação de um questionário constituído de doze questões - nessa etapa foram obtidas 52 respostas, sendo que 19 instituições afirmaram possuir RI e 33 instituições afirmaram não possuir RI; na terceira etapa adotou-se como técnica de coleta de dados a observação direta dos sites institucionais das 50 IES que não responderam ao questionário eletrônico, nessa etapa foram identificados 15 repositórios institucionais. O estudo mostra que a disseminação da produção científica da instituição, apontada por todas as 19 instituições que afirmaram possuir RI, como o principal fator para a sua implantação. Entretanto, a principal dificuldade encontrada para a implantação dos RIs, destacada nesse trabalho, explicita a falta de recursos humanos capacitados nas IES públicas do país para trabalharem na construção e no gerenciamento de repositórios. Com o estudo percebe-se apenas 33,3\% das IES pesquisadas possuem RI.
\end{abstract}

Palavras-chave: Repositórios institucionais. Comunicação Científica. Acesso livre ao conhecimento. Gestão do conhecimento científico. Instituições de Educação Superior.

\section{THE ROLE OF THE ACADEMIC LIBRARIES IN SCIENTIFIC COMMUNICATION: A STUDY OF INSTITUTIONAL REPOSITORIES}

\begin{abstract}
This is a work of literature review, followed by a survey conducted through a structured questionnaire with open and closed questions, with the purpose of obtaining information about the outlook for implementation of institutional repositories of open access to scientific information by universities of Brazil. The research was divided into three steps: analysis of 102 institutional sites identified by the e-MEC system seeking the location of the e-mail to contact the libraries, a questionnaire consisting of twelve issues - at this stage were obtained 52 responses, 19 institutions that reported having $I R$ and $33 I R$ institutions said that they have, in the third step was adopted as a technique for data collection direct observation of institutional sites of the 50 HEIs that have not responded to the electronic questionnaire, 15 were identified at this stage institutional repositories. The study shows that the spread of scientific institution was reported by all 19 institutions that reported having IR, as the main factor for its implementation. However, the main difficulty for the implementation of IRs, highlighted in this work, explains the lack of trained human resources in public higher education institutions in the country to work in building and managing repositories. With this study we can observe only 33.3\% of the universities surveyed have IR.
\end{abstract}

Keywords: Institutional repositories. Scientific Communication. Free access to knowledge. Management of scientific knowledge. Institutions of Higher Education.

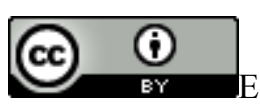

Esta obra está licenciada sob uma Licença Creative Commons

\footnotetext{
${ }^{\mathrm{i}}$ Universidade Federal do Rio de Janeiro.patriciamarra1@gmail.com 174

Enc. Bibli: R. Eletr. Bib. Ci. Inf., ISSN 1518-2924, Florianópolis, v. 17, n. esp. 2 - III SBCC, p. 174-194, 2012.
} 


\section{INTRODUÇÃO}

A sociedade está passando por diversas transformações sociais, econômicas, políticas e, principalmente, tecnológicas. Neste novo contexto - a sociedade da informação - percebese a importância cada vez maior que a informação passou a desempenhar, onde a comunicação torna-se fundamental para o progresso dos diversos níveis e setores da sociedade. A respeito da sociedade da informação, Araújo e Dias (2011, p. 111) afirmam que:

Em 1973, Daniel Bell, em sua obra O surgimento da sociedade pós-moderna, afirma que o ponto central da sociedade pós-moderna é o surgimento das atividades de produção de conhecimento e informação. [...] A partir desse fato, o termo sociedade de informação se difunde e se define como a etapa do desenvolvimento da sociedade que se caracteriza pela abundância de informação organizada. $\mathrm{O}$ espaço de produção desta sociedade não é mais o da fábrica ou do escritório, mas o conjunto de meios, que é, antes de tudo, um conjunto de informações, mais especificamente, de informações científicas, tecnológicas, comerciais, financeiras e culturais, difundidas de forma rápida e interativa.

$\mathrm{Na}$ sociedade da informação os processos de obtenção e de compartilhamento da informação ocorrem de forma rápida e flexível. Nesse novo contexto, construído com base nas Tecnologias de Informação e Comunicação (TIC's), nota-se o importante papel que tais tecnologias desempenham na democratização do acesso à informação, principalmente através da Internet. Percebe-se que o desenvolvimento acelerado da rede mundial de computadores causou enormes impactos em diversas esferas da sociedade, dentre as quais podemos citar a comunicação científica, atividade essencial para o progresso de um país.

As Instituições de Ensino Superior (IES) podem ser consideradas como uma das maiores e mais importantes instituições produtoras de conhecimento científico que um país pode ter, no entanto a disseminação das informações científicas produzidas nesse ambiente não tem ocorrido de maneira viável. Porém, a internet como uma ferramenta das TIC's, pode proporcionar às IES uma nova alternativa para disseminar a produção científica gerada por seu corpo docente e discente.

A dificuldade e a restrição observadas em torno da divulgação dos resultados de pesquisas realizadas em âmbito acadêmico estão relacionadas com questões e interesses de determinados atores da comunidade científica. Como opção para facilitar a transmissão do conhecimento científico, são propostas iniciativas de construção repositórios institucionais, vistos como uma ferramenta de gestão do conhecimento científico com capacidade para ampliar a visibilidade da informação científica.

A análise e o mapeamento do atual cenário da produção e da comunicação científica no país são de extrema relevância, uma vez que se faz necessário a existência de mais 
iniciativas voltadas para a questão do acesso livre à informação científica produzida em âmbito nacional. Pretende-se apresentar a atual relação entre as IES públicas brasileiras e o paradigma do acesso livre à informação científica produzida no ambiente acadêmico.

Acredita-se que o resultado desse estudo possa contribuir com informações sobre o panorama de implantação de repositórios institucionais de acesso livre à informação científica pelas Instituições de Educação Superior públicas do país. Para tanto, serão abordadas experiências de universidades públicas brasileiras que implementaram iniciativas de repositórios institucionais.

\section{CIÊNCIA E COMUNICAÇÃO}

A comunicação científica é um processo crucial para o desenvolvimento da ciência e para a atualização dos profissionais das diversas áreas do conhecimento. Diante da diversidade de conceituações encontradas para o termo 'comunicação científica', cunhado por John Bernal na década de 1940, a definição que será adotada no presente trabalho refere-se a:

[...] Comunicação que incorpora as atividades associadas à produção, disseminação e uso da informação, desde o momento em que o cientista concebe uma idéia para pesquisar até que a informação acerca dos resultados é aceita como constituinte do estoque universal de conhecimentos. (GARVEY; GRIFFITH, 1979 apud TARGINO, 2000, p.10).

Partindo do princípio de que a comunicação científica é um processo que visa à disseminação da informação, é importante que haja disponibilidade de canais para possibilitar que esta ação aconteça de maneira eficaz, de maneira que possa abranger o maior número possível de interessados.

Os canais de comunicação da informação podem ser de natureza formal, superformal, informal ou semiformal. De acordo com Targino (2000), a comunicação científica formal se dá através de diversos meios de comunicação escrita, com destaque para livros, periódicos, obras de referência em geral, relatórios técnicos, revisões de literatura, bibliografias de bibliografias etc. Já o domínio superformal refere-se aos livros, como conhecimento avaliado e absorvido pela comunidade científica, junto às publicações secundárias e terciárias. A comunicação informal é a transferência da informação através de contatos interpessoais e de quaisquer recursos destituídos de formalismo, como reuniões científicas, participação em associações profissionais e colégios invisíveis. Por fim, a comunicação semiformal pode ser entendida como aquela que possui simultaneamente, aspectos formais e informais, e que, 
como a informal, possibilita discussão crítica entre os pares, o que conduz a modificações ou confirmações do teor original.

Embora os membros da comunidade científica utilizem, ainda hoje, os periódicos científicos como o principal canal formal de divulgação dos resultados de pesquisas, percebese que esse tipo tradicional de fonte de informação apresenta algumas restrições, que dificultam o processo de comunicação da ciência. A importância do periódico na comunicação formal da ciência deve-se à seriedade e formalidade com que são selecionados os artigos que irão compor suas edições. Todos os artigos passam por um complexo processo de submissão e rigorosa avaliação dos pares antes de serem aceitos para publicação. A morosidade com que ocorre tal processo é uma barreira ao desenvolvimento do ciclo da comunicação científica, pois de acordo com Mueller (2007, p. 76) a "demora na publicação do artigo, às vezes, chega a ser de um ano após o recebimento do original pelo editor".

De acordo com Meadows (1999, p. 1):

A maneira como um cientista transmite informações depende do veículo empregado, da natureza das informações e de seu público-alvo. Da mesma forma que, com o passar do tempo, isso sofre mudanças, também sofrem alterações a formulação e o acondicionamento das informações.

A internet é um veículo de informação que causou diversas mudanças no ciclo da comunicação cientifica, tornando a troca de informações entre pesquisadores um processo menos dispendioso e demorado, o que beneficia o desenvolvimento científico.

Os resultados mostraram que a internet afeta significativamente o ciclo da comunicação científica, não somente na rapidez com que a informação pode ser recuperada, mas também na comunicação entre os pares, tida como a etapa que mais passou por mudanças desde o recente advento da internet no mundo acadêmico brasileiro. (CUENCA; TANAKA 2005, p. 845).

A informação é uma necessidade social e atualmente a internet é a ferramenta com maior potencialidade para facilitar e ampliar a disseminação e o acesso à informações sobre as mais diversas áreas do conhecimento.

Diante do acelerado desenvolvimento das TIC's, emergem novos canais de comunicação da informação, que visam tornar a divulgação do conhecimento científico um procedimento mais rápido, flexível e menos complexo, como é o caso das publicações eletrônicas. Entretanto,como observa Mueller (2006), o processo de legitimação da publicação eletrônica como elemento reconhecido no sistema de comunicação cientifica é um enorme desafio, porém a legitimidade já parece ter sido atribuída aos periódicos eletrônicos que seguem o modelo tradicional, ou seja, do formato impresso de publicação do periódico científico. Nota-se também o desenvolvimento de iniciativas de implantação de bibliotecas 
digitais e de repositórios institucionais, que têm como objetivo minimizar as barreiras que impedem a proliferação da informação, além de visarem à socialização do acesso ao conhecimento. Na perspectiva da socialização do conhecimento científico Leite (2009, p. 29) afirma que:

Um repositório institucional conjuga aspectos da comunicação científica formal e informal. Um dos argumentos dessa abordagem reforça que o conhecimento científico não é produzido exclusivamente a partir daquilo que já foi avaliado e é publicado formalmente, mas também daquilo que é veiculado informalmente, tornando mais flexível, portanto, a comunicação científica.

Dentre os diferentes canais existentes para viabilizar a comunicação científica, destaca-se o periódico científico, porém os repositórios institucionais têm, mesmo que ainda de forma prematura, conquistado um importante espaço no ciclo da comunicação científica. Portanto, vemos emergir uma nova ferramenta de divulgação da ciência, que tem sido reconhecida pelos diversos atores da comunidade científica, principalmente pelas universidades, que percebem uma nova possibilidade para ampliar a visibilidade das pesquisas desenvolvidas no ambiente acadêmico.

\section{PRODUÇÃO CIENTÍCIA BRASILEIRA E AS IES}

O Relatório UNESCO sobre ciência 2010 apresenta o Brasil como o $13^{\circ}$ maior produtor de ciência do mundo, afirma também que os cientistas brasileiros publicaram 26.482 artigos científicos em periódicos indexados pelo Thomson Reuter's Science Citation Index em 2008, sendo que mais de $90 \%$ desses artigos foram gerados em universidades públicas.

As pesquisas desenvolvidas em universidades e financiadas por agências de fomento à pesquisa contribuem para o desenvolvimento nacional e podem ser vistas como uma forma de ampliar a visibilidade e o reconhecimento nos mesmos patamares de outros países. Como podemos observar na figura 1 , o setor que recebe mais investimentos governamentais é o de pesquisa em nível superior. Percebemos assim a importância que as universidades têm no contexto nacional, vistas como essenciais para o desenvolvimento e a afirmação do país, desempenham a função de principal centro de produção do conhecimento e do avanço científico. 


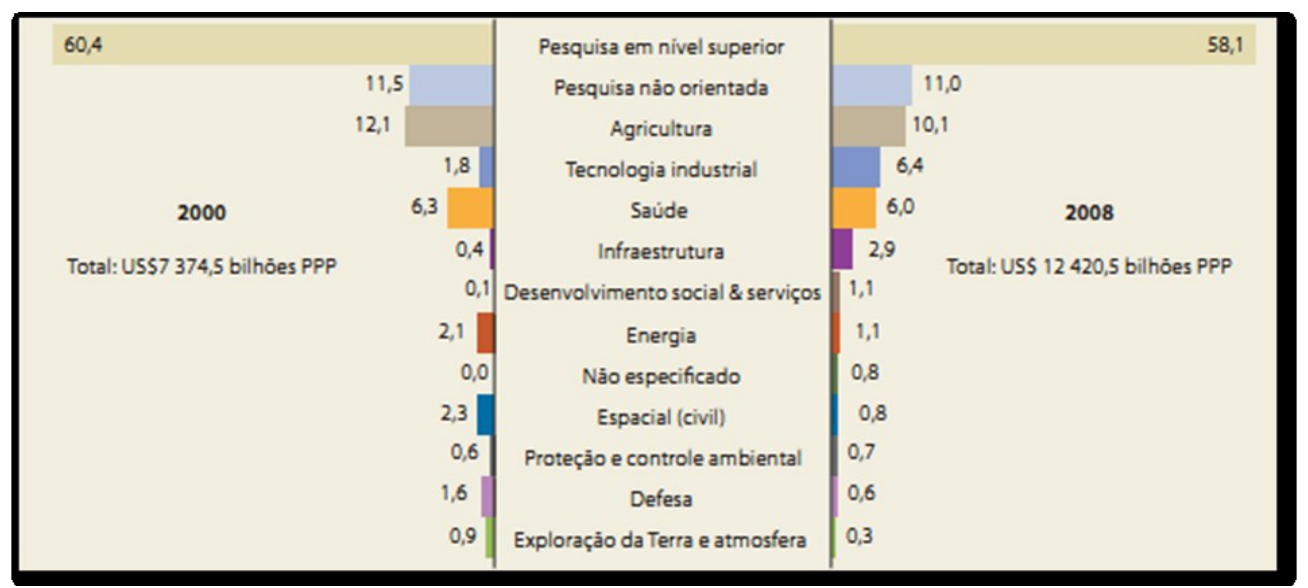

Figura 1: Investimento governamental por objetivo socioeconômico em 2000 e 2008 - Fonte: (UNESCO, 2010, p. 35).

Os pesquisadores brasileiros são em grande parte membros das IES, como exposto na figura 2. No ambiente acadêmico a produção científica provém dos trabalhos desenvolvidos por estudantes de pós-graduação, que frequentemente são financiados pelas universidades e agências de fomento; por docentes - estes que são obrigados a publicar um número determinado de artigos por ano para melhorar seu currículo, aumentar seu prestígio junto à comunidade acadêmica e ampliar a visibilidade da instituição a que pertencem e por estudantes de graduação.

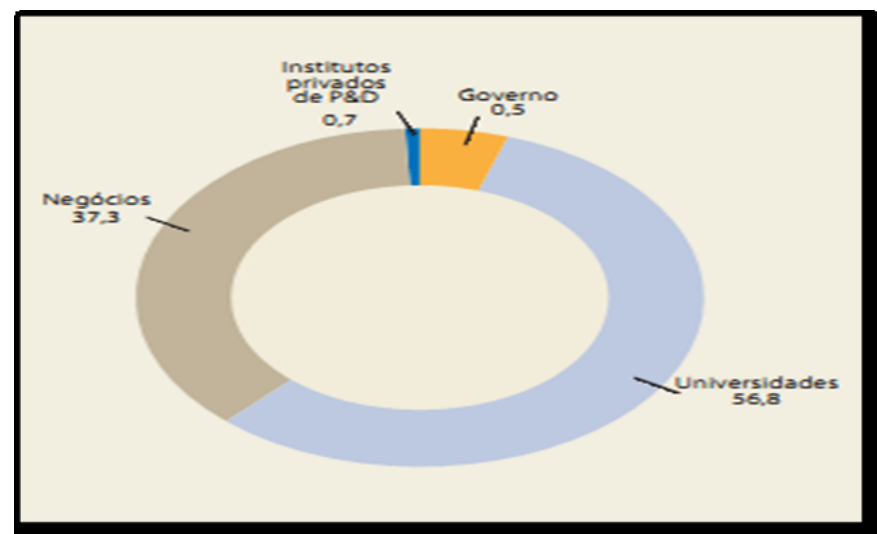

Figura 2: Pesquisadores no Brasil por setor de atividade, referente ao ano de 2008 (\%) - Fonte: (UNESCO, 2010, p. 41)

No Brasil os investimentos públicos em Pesquisa e Desenvolvimento (P\&D) são amplamente direcionados ao setor acadêmico, mais especificamente ao financiamento de pesquisas para a pós-graduação. A baixa divulgação dos resultados dessas pesquisas para a sociedade é um fator preocupante, visto que o dinheiro que o governo utiliza para financiar tais estudos é proveniente dos impostos pagos pela sociedade. Dessa forma a disseminação gratuita da informação científica deveria ser entendida como uma obrigação do governo para com a sociedade, tornando assim a comunicação científica um processo menos complexo. 
A adoção de repositórios institucionais tem crescido em todos os países, particularmente ao nível das universidades para as quais representam uma oportunidade de aumentar a visibilidade dos seus investigadores/professores e da própria instituição, ao mesmo tempo que prestam um serviço público, disponibilizando de forma gratuita as publicações decorrentes da sua atividade científica, dessa forma respondendo à crescente exigência de justificação dos fundos e investimentos públicos que lhes são atribuídos. (GOMES; ROSA, 2010, p. $153)$.

As IES começam a perceber o potencial dos repositórios institucionais como um agente facilitador e maximizador do processo de democratização e disseminação do conhecimento científico na sociedade, visando o acesso livre à informação de caráter científico.

\section{OS REPOSITÓRIOS INSTITUCIONAIS}

No começo da década de 1990 um grupo de pesquisadores do Los Alamos National Laboratory (LANL), nos Estados Unidos, desenvolveu a primeira iniciativa de repositório para abrigar os preprints - artigos que ainda não foram publicados oficialmente e não foram avaliados pelos pares - na área de física, denominado ArXiv, que atualmente está vinculado a Universidade de Cornell e abrange preprints nas áreas de física, matemática, ciência da computação, biologia quantitativa, finanças quantitativas e estatísticas. Logo após da criação do $\mathrm{ArXiv}$ diversas iniciativas de repositórios começaram a surgir em todo o mundo, com isso percebe-se a necessidade de haver um modelo de interoperabilidade para integrar esses repositórios.

No ano de 1999 aconteceu a Convenção de Santa Fé, onde foi criado o modelo Open Archives Initiative e se discutiu soluções que viabilizassem a interoperabilidade entre as iniciativas de repositórios digitais de e-prints. Diversos acontecimentos marcaram a trajetória da $O A I$, que contou com algumas declarações em âmbito internacional, dentre as quais podemos destacar como sendo as mais significativas: a Budapest Open Access Initiative (BOAI) divulgada em 2001, a Bethesda Statement on Open Access Publishing e a Berlin Declaration on Open Access to Knowledge in the Sciences and Humanities, ambas divulgadas em 2003. Essas três declarações são frequentemente denominadas como "Declarações BBB". A BOAI, "Movimento que definiu duas estratégias básicas, ambas baseadas no uso do protocolo Open Archives Initiative Protocol for Metadata Harvesting (OAI-PMH)." (COSTA, 2006, p. 41). Essas duas estratégias que pretendem dar visibilidade à produção científica são conhecidas como: auto-arquivamento e periódicos eletrônicos de acesso livre, o primeiro 180

Enc. Bibli: R. Eletr. Bib. Ci. Inf., ISSN 1518-2924, Florianópolis, v. 17, n. esp. 2 - III SBCC, p. 174-194, 2012. 
viabilizado pela via verde (green road) - e o segundo viabilizado pela via dourada (golden road). De acordo com a BOAI (2002 apud TOMAÉL, 2008, p. 127) essas estratégias:

[...] são viabilizadas por intermédio da implementação de dois modelos: 1) golden road, baseado no sistema tradicional de comunicação científica, fundamentado na revisão pelos pares (peer-review), ou seja, os periódicos científicos de acesso aberto (OAJ - Open Archives Journals); 2) green road, baseado no autoarquivamento, em repositórios, de pre-prints ou de pós-prints, neste último caso, depositados com autorização das editoras.

A via verde e a via dourada representam um grande benefício para os autores de artigos científicos, pois estes publicam os resultados de suas pesquisas como forma de ampliarem a visibilidade de seus trabalhos e para que assim possam ser citados em publicações de outros pesquisadores. Quando o acesso a um artigo é feito mediante pagamento de assinaturas, tal prática mostra-se como um problema, pois o número de pessoas que têm acesso as publicações é relativamente pequeno, causando prejuízo tanto para o autor que não terá a visibilidade desejada para seu trabalho como para outros pesquisadores que por não terem acesso aos periódicos científicos pagos, deixaram de utilizar trabalhos que poderiam contribuir com dados relevantes para suas pesquisas.

Partindo do princípio que a filosofia da iniciativa dos arquivos abertos promove maior acessibilidade às informações e proporciona o aumentando da visibilidade das pesquisas científicas em âmbito nacional e internacional, é possível afirmar que esses dois componentes - acessibilidade e visibilidade - são fatores que norteiam a construção de repositórios digitais e são elementos capazes de proporcionar a ruptura do modelo de comunicação científica ainda vigente.

A mudança no ciclo de comunicação científica, causada pela ruptura do modelo de comunicação científica ainda vigente tem privilegiado a comunicação científica informal, o que proporciona diversos benefícios, entre eles a divulgação da chamada literatura cinzenta (grey literature). De acordo com Gomes; Mendonça; Souza (2000, p. 97) a literatura cinzenta é constituída por documentos que têm pouca probabilidade de ser adquirido através de canais usuais de venda de publicações, diferente do que acontece com a literatura branca, que é constituída por documentos convencionais ou formais. Portanto, a literatura cinzenta pode ser vista como um importante canal de comunicação científica, constituída pelos seguintes tipos de documentos: dissertações, teses, publicações governamentais, preprints, comunicações em eventos, relatórios técnicos, relatórios de pesquisa, e outros documentos de publicação restrita. 
No novo ciclo da comunicação científica proposto pela via verde, há a inserção de um novo canal para divulgação científica, o repositório institucional. A definição de RI que será adotada no presente estudo refere-se a:

Um repositório institucional de acesso aberto constitui, portanto, um serviço de informação científica - em ambiente digital e interoperável - dedicado ao gerenciamento da produção intelectual de uma instituição. Contempla, por conseguinte, a reunião, armazenamento, organização, preservação, recuperação e, sobretudo, a ampla disseminação da informação científica produzida na instituição. (LEITE, 2009, p. 21).

Os repositórios podem ser entendidos como uma ferramenta capaz de armazenar, preservar e proporcionar acesso livre a toda produção científica de uma determinada instituição. Os RIs são construídos com base na iniciativa dos arquivos abertos e no paradigma do acesso livre à informação, sendo percebido como uma resposta de alguns atores envolvidos no processo de comunicação científica aos altos valores cobrados pelas editoras de periódicos científicos, valores esses que são vistos como uma barreira ao desenvolvimento científico.

O aperfeiçoamento das TIC que facilitou a disseminação e acessibilidade da informação, e a criação de barreiras associadas aos elevados valores cobrados por parte das grandes editoras que controlavam o mercado das publicações cientificas foram fatores decisivos para o surgimento do Movimento do acesso livre - Open Access Movement $(O A M)$ - referente às publicações científicas. (GOMES; ROSA, 2010, p. 155).

$\mathrm{Na}$ construção de um repositório institucional é fundamental que se estabeleça uma abordagem, as quais Leite (2009) denomina rígida e flexível. A abordagem a ser adotada deve estar de acordo com as funções que a instituição espera que o RI atenda, portanto é imprescindível que os responsáveis pelo seu planejamento e implantação avaliem as vantagens e desvantagens de cada abordagem. A abordagem rígida preconiza a disseminação da comunicação científica formal, ou seja, principalmente dos artigos científicos, que passaram por um processo de avaliação pelos pares. A abordagem flexível propõe a disseminação tanto da comunicação científica formal como da comunicação científica informal. Muitos repositórios possuem um modelo de organização flexível, porém é importante lembrar que a flexibilidade não implica na inserção de qualquer documento produzido em âmbito acadêmico no RI.

Para que um determinado repositório possa atender as necessidades da instituição mantenedora e às necessidades informacionais de seus usuários faz-se necessário que após o estabelecimento de uma abordagem rígida ou flexível, haja o estabelecimento de uma política de funcionamento do repositório antes da sua implantação. 
Atualmente há no mercado diversas plataformas open source direcionadas para implementação de repositórios institucionais, como DSpace, Eprints e Fedora. No Brasil o DSpace é o mais difundido sistema de gerenciamento de publicações eletrônicas, criado pelo MIT Libraries em conjunto com a Hewlee-Pankard, é um software livre que está disponível gratuitamente. O Instituto Brasileiro de Informação em Ciência e Tecnologia é responsável pela customização e distribuição da versão do software em língua portuguesa no país. De acordo com IBICT o DSpace é "um repositório digital que captura, armazena, indexa, preserva e redistribui a informação de uma instituição em formato digital". Uma das características mais importantes para a escolha dessa plataforma é sua capacidade de armazenar diversos formatos e conteúdos. Outra característica importante do DSpace é a adoção de padrões tecnológicos como o Protocolo de Intercâmbio de Informações OAI-PMH (Protocol for Metadata Harvesting) e padrões de metadados (Dublin Core), importantes para que haja uma perfeita troca de informações entre repositórios digitais.

No âmbito da construção e gerenciamento de RIs no Brasil, é notória a importância do Diretório de Políticas de Acesso Aberto das Revistas Científicas Brasileiras (DIADORIM), que tem como objetivo:

[...] identificar, sistematizar e disponibilizar as informações das políticas estabelecidas pelas editoras dos periódicos brasileiros referentes ao armazenamento dos artigos nos repositórios institucionais. Constitui-se em uma fonte de consulta importante para que autores e gestores de repositórios não descumpram o acordo de publicação estabelecido entre o autor e a revista, quando do arquivamento de artigos no repositório da instituição. (IBICT).

O IBICT por meio de iniciativas como a criação do Manifesto brasileiro de apoio ao acesso livre à informação científica, a distribuição da versão do DSpace em língua portuguesa no Brasil e a implantação do DIADORIM, mostra-se como um importante incentivador do acesso livre à informação científica no Brasil

No Brasil o Movimento de Acesso Livre à Informação Científica conta também com importante instrumento de incentivo, o projeto de lei PL 1120/2007, que obriga todas IES públicas a construírem repositórios institucionais para depósito da produção técnico-científica da instituição, porém o projeto de lei foi arquivado em 01 de fevereiro de 2011 . No mês de julho de 2011, o senador Rodrigo Rollemberg, mesmo autor do PL 1120/2007, apresentou um novo projeto, o PLS - Projeto de Lei do Senado 387/2011, que:

Obriga as instituições de educação superior de caráter público, bem com as unidades de pesquisa a construir repositórios institucionais de acesso livre, nos quais deverão ser depositados o inteiro teor da produção técnico-científica conclusiva dos estudantes aprovados em cursos de mestrado, doutorado, pós-doutorado ou similar, assim como da produção técnico-científica, resultado de pesquisas científicas realizadas por professores, pesquisadores e colaboradores, apoiados com recursos 
públicos para acesso livre na rede mundial de computadores; entende-se por produção técnico-científica monografias, teses, dissertações e artigos publicados em revistas, nacionais e internacionais, com revisão por pares. (BRASIL, 2011).

O senador Cristovam Buarque foi designado relator do PLS 387/2011 no dia 14 de Julho de 2011 e atualmente este PLS encontra-se na Comissão de Ciência, Tecnologia, Inovação, Comunicação e Informática (CCT) aguardando aprovação. Os projetos de lei não são as únicas ações existentes no país, há também o Instituto Brasileiro de Informação em Ciência e Tecnologia (IBICT), que entre inúmeras iniciativas, lançou o Manifesto Brasileiro de apoio ao Acesso Livre à informação científica em 2005, além de ter lançado em dezembro de 2008 um edital para a distribuição de equipamentos às universidades e institutos de pesquisa públicos, com a finalidade de promover a construção e implantação de RIs.O Coordenador Geral de Projetos Especiais do IBICT, Hélio Kuramoto, é um importante entusiasta do modelo de acesso livre à informação científica e realiza um respeitável trabalho mantendo um blog dedicado às questões relacionadas ao acesso livre à informação científica.

As iniciativas em prol da promoção dos repositórios sob o princípio do livre acesso à informação são as mais variadas possíveis, portanto ressalta-se a importância de analisar o atual cenário de construção de RIs pelas IES públicas brasileiras.

\section{A PESQUISA}

O presente estudo buscou identificar as Instituições de Ensino Superior públicas brasileiras que possuem iniciativas de repositórios institucionais. Foi utilizado o sistema eMEC - sistema eletrônico do Ministério da Educação e Cultura para acompanhamento dos processos que regulam a educação superior no Brasil - para identificar as IES públicas brasileiras. A pesquisa foi dividida em três etapas. Na primeira etapa foi realizada uma análise dos sites institucionais das 102 IES identificadas pelo sistema e-MEC visando à localização do e-mail para contato das bibliotecas. Tendo em vista a dificuldade de localizar o e-mail para contato direto com as bibliotecas de determinadas instituições, nessa etapa também foram utilizadas as redes sociais Twitter e Facebook para obter contato com a equipe dessas bibliotecas, prática que se mostrou bastante eficaz e otimizou o processo de comunicação com os bibliotecários.

$\mathrm{Na}$ segunda etapa do estudo foi elaborado um questionário constituído de doze questões, utilizado como instrumento de coleta de dados. O questionário eletrônico foi 
encaminhado as bibliotecas, via Internet, durante o período de 29 de agosto de 2011 a 23 de setembro de 2011. Nessa etapa foram obtidas 52 (cinqüenta e duas) respostas, resultando em índice de retorno de 50, 9\%.

No desenvolvimento da terceira etapa adotou-se como técnica de coleta de dados a observação direta dos sites institucionais das 50 (cinqüenta) IES que não responderam ao questionário eletrônico, além do uso do Diretório do IBICT - lista com todos os repositórios institucionais que utilizam o Sistema Dspace - e da utilização dos mecanismos de busca na internet, Google e Yahoo, a fim de identificar se estas universidades possuem repositórios institucionais. A observação direta aconteceu no período entre 24 de setembro de 2011 a 28 de setembro de 2011.

\subsection{Apresentação e discussão dos dados obtidos com a aplicação do questionário eletrônico}

As 102 IES públicas brasileiras que fizeram parte da amostra são de quatro categorias: comunitárias, estaduais, federais e municipais (gráfico 1).

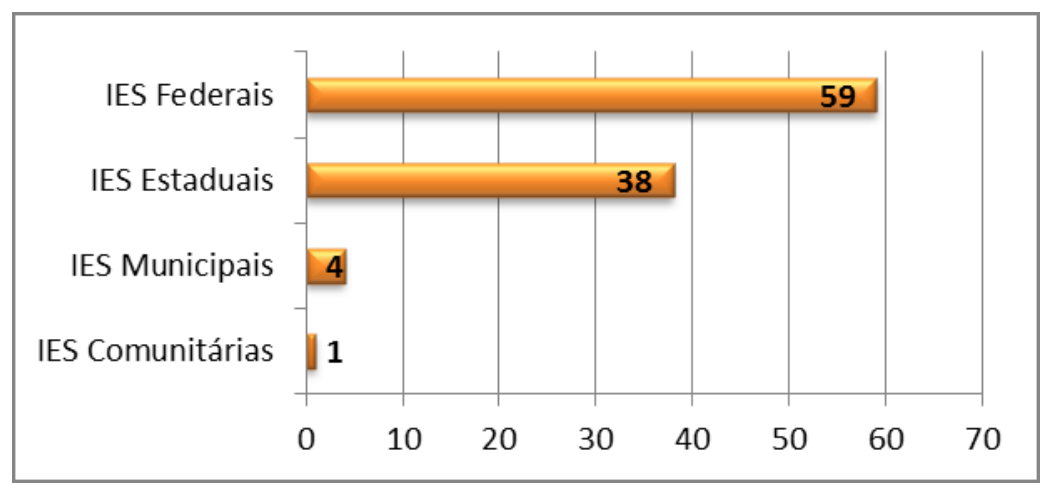

Gráfico 1: Instituições de Ensino Superior Analisadas

$\mathrm{Na}$ segunda etapa do estudo, na qual se deu a aplicação do questionário eletrônico, foram obtidas 52 respostas, sendo que 19 instituições afirmaram possuir RI e 33 instituições afirmaram não possuir RI. Durante a pesquisa notou-se o interesse de diversos bibliotecários, de instituições que não têm repositórios, em conhecer mais sobre a temática para que possam ter subsídios para a elaboração de projetos de implantação de RIs. Algumas instituições respondentes afirmaram ter RI, porém com a análise do mesmo, percebeu-se que se tratava de uma Biblioteca Digital de Teses e Dissertações e nessa pesquisa estas não foram consideradas BDTDs. 
A construção de repositórios institucionais foi impulsionada no final de 2009, o que ocorreu com a primeira distribuição dos kits tecnológicos para construção de repositórios, além do encontro presencial com representantes das instituições para tratar as diretrizes para a elaboração e desenvolvimento de um plano de trabalho para implantação dos repositórios (IBICT, 2010). Em 2010, mais especificamente em novembro, houve o lançamento, em conjunto, dos repositórios institucionais das 33 instituições públicas de ensino e pesquisa contempladas com os kits tecnológicos (IBICT, 2010). Estas ações podem explicar o alto índice de implantação de repositórios institucionais no ano de 2010 como mostra o gráfico 2.

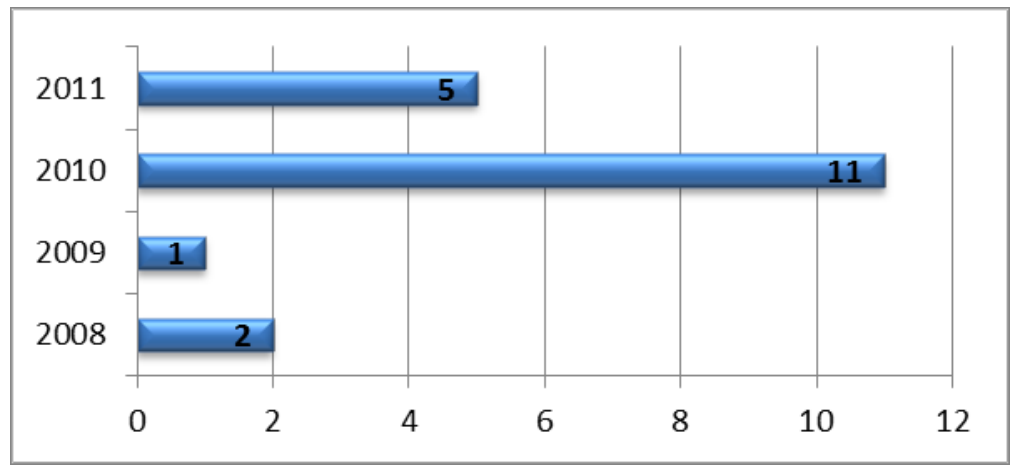

Gráfico 2: Quantidade de RIs implantados por ano

A construção de um repositório está condicionada a um ou mais fatores. Diante dos dados obtidos com a pesquisa percebe-se que a questão da disseminação da produção científica foi o fator central para as IES implantarem seus RIs, pois foi a única alternativa das quatro colocadas no questionário - sendo as outras contribuir para o acesso aberto à informação científica no Brasil; aumentar a visibilidade das pesquisas científícas da instituição; preservar a memória institucional (Conservação de documentos fidedignos e acessíveis a longo prazo) - que foi assinalada por todos os 19 respondentes. Enquanto que a questão da preservação da memória institucional obteve o menor índice de resposta, com 14 indicações (quadro 1) o que mostrou-se interessante, pois a preservação da memória institucional das universidades é uma questão que está intimamente ligada à implantação de repositórios institucionais e de acordo com Sayão et al. (2009, p. 39):

Uma das mais importantes motivações para a criação dos repositórios institucionais é assegurar que os materiais digitais de pesquisa permaneçam disponíveis e acessíveis por longo prazo, contribuindo para a construção e preservação da memória acadêmica das instituições de pesquisa e ensino. Nessa direção, espera-se que os repositórios digitais disponham de metodologias e ferramentas que mantenham íntegros estes estoques por longo prazo. A norma mais importante da área é o Open Archival Information System (OAIS), um modelo conceitual desenvolvido pela NASA e tornado uma norma ISO em 2002. 
A preservação digital é uma questão que merece bastante atenção por parte da equipe que administra o repositório, visto que a obsolescência tecnológica é um risco constante à continuidade de qualquer acervo digital. Em relação à preservação digital há também a questão da segurança da informação que está relacionada com criação e conservação de documentos fidedignos e acessíveis a longo prazo e que Sayão et al.(2009, p. 43) define como: "a capacidade do sistema de atender aos requisitos de segurança da instituição e assegurar a integridade física dos estoques de conteúdos digitais e intervenções e acessos indevidos".

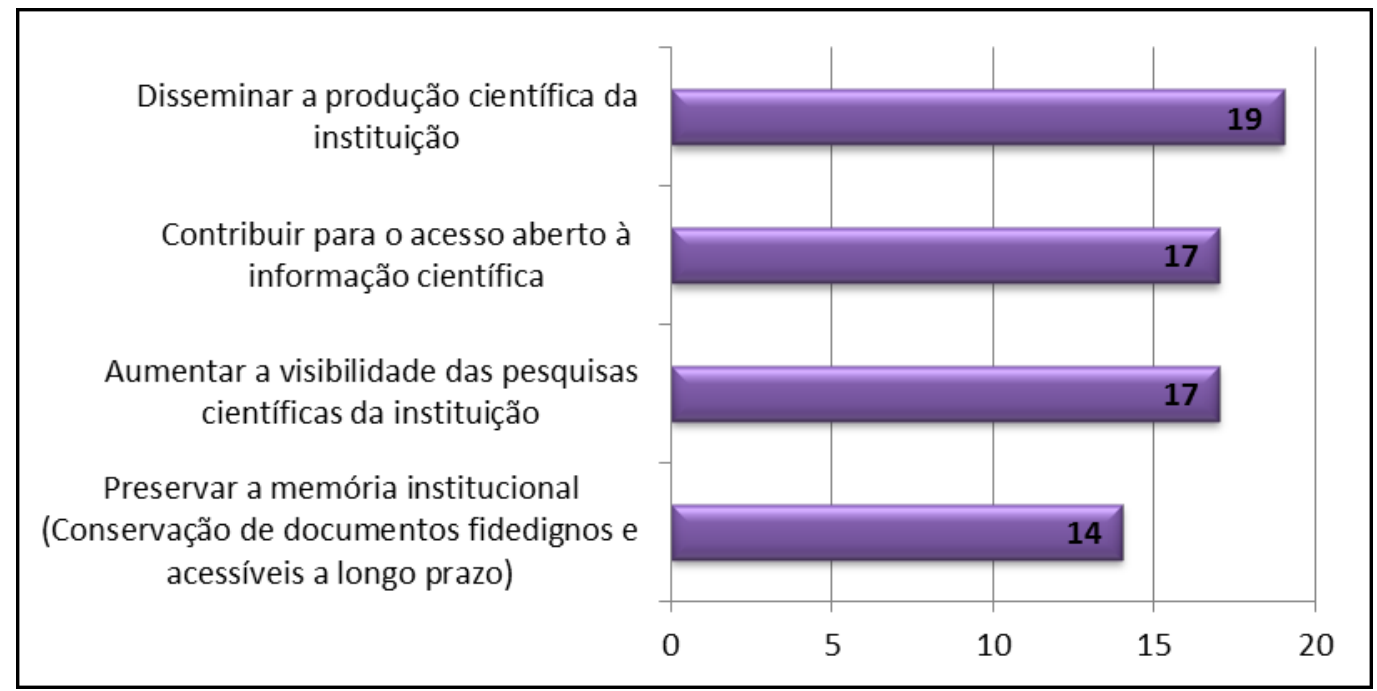

Gráfico 3: Fatores determinantes para a implantação do RI

A determinação da política institucional de informação consiste em uma das fases mais importantes no desenvolvimento de um repositório institucional. De acordo com Silva (2008, p. 3): “As políticas de informação para Repositórios Institucionais são fundamentais para a definição de diretrizes que dizem respeito, principalmente, a aspectos técnicos, da instituição e da comunidade envolvida da qual o repositório será destinado". Das 19 IES respondentes que têm RI, 14 afirmam ter uma política de informação estabelecida, 1 afirma que está em fase de desenvolvimento da política, enquanto que 4 IES afirmam que ainda não possuem. $\mathrm{O}$ estabelecimento da política orienta o desenvolvimento e gerenciamento das coleções, além de definir características como tipos de documentos que serão armazenados, as formas de depósito desses documentos e a forma de acesso aos conteúdos depositados.

O direito autoral é um tema contemporâneo que tem provocado inúmeras discussões e por isso é um elemento que deve fazer parte da política de informação do RI, além de estar em conformidade com a legislação. Ao contrário das editoras científicas comerciais, que percebem o direito autoral como uma forma de garantir o lucro financeiro, a grande questão 
que envolve os direitos autorais dos documentos arquivados em RIs tem haver com a ampliação da visibilidade dada ao seu trabalho, já que este pode ser acessado e reproduzido. Autores que depositam seus trabalhos em repositórios têm no direito autoral uma proteção contra o plágio, pois o copyright é uma maneira de garantir que seu trabalho seja reconhecido. A pesquisa realizada identificou que políticas de depósito utilizadas pelos repositórios são: Autoarquivamento (Depósito de conteúdos realizado pelos próprios autores) - prática utilizada por 4 repositórios; o autor submete o conteúdo à equipe responsável pelo repositório, que por sua vez realiza o depósito - prática utilizada 14 repositórios; rastreamento das publicações disponíveis com licença Creative Commons ${ }^{2}$ - prática utilizada por 1 repositório.

A prática de autoarquivamento não significa que qualquer documento seja inserido no RI. O autor deposita seu trabalho no repositório, porém o documento é avaliado pela equipe que gerencia o repositório que decidirá se o documento irá ou não compor a coleção digital.

Segundo Leite (2009, p. 37): "na maioria dos países, a criação de repositórios institucionais tem sido uma iniciativa que parte ou é realizada nas bibliotecas das instituições de ensino e pesquisa". A pesquisa identificou que 18 dos 19 repositórios institucionais que fizeram parte da amostra são vinculados à biblioteca, enquanto que em apenas 1 caso não há esse vínculo. A equipe responsável pelo gerenciamento do repositório, habitualmente é formada por bibliotecários, porém como afirma Barton (2004, apud GOMES; ROSA, 2010, p. 161) é importante que essa equipe seja multidisciplinar, ou seja, formada por bibliotecários, analistas de informação, administradores de arquivos, administradores de departamentos e da instituição, pesquisadores e pessoal envolvido com a política universitária e que promova a utilização do RI. Na pesquisa identificou-se que há bibliotecários em todas as 19 equipes, o que para Sayão et al. (2009, p. 176) "Certamente ocorre por que os processos envolvidos nas rotinas de um repositório institucional possuem natureza muito próxima e similar aos trabalhos desenvolvidos em ambientes digitais por bibliotecas e bibliotecário".

\footnotetext{
${ }^{2}$ A Creative Commons é uma organização não governamental sem fins lucrativos que disponibiliza licenças flexíveis para obras intelectuais, facilitando as questões concernentes aos direitos autorais na perspectiva do acesso livre à informação. 188 


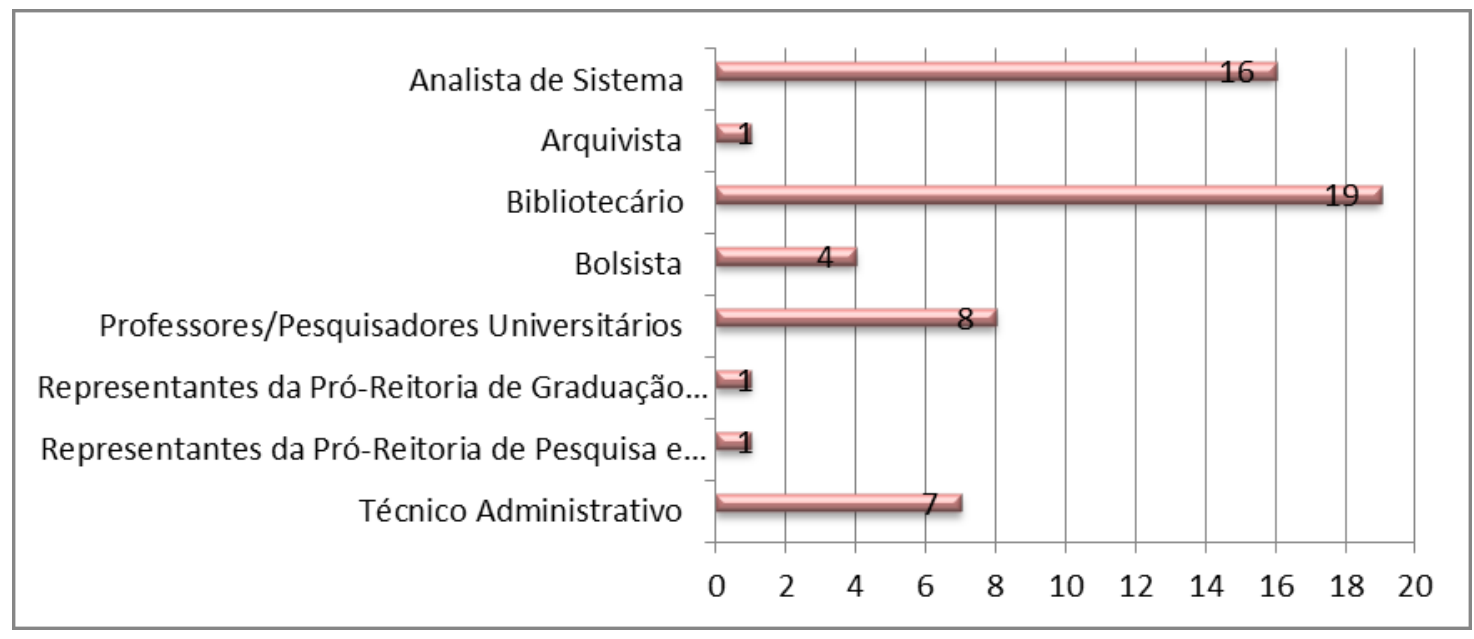

Gráfico 4: Equipe responsável pelo funcionamento/gerenciamento do RI

Os documentos armazenados em um repositório podem ser de diversos tipos, portanto a presente pesquisa se propôs a conhecer quais são os mais difundidos nos RIs das universidades brasileiras. Tendo como base para comparação o universo dos repositórios científicos portugueses, que de acordo com Gomes e Rosa (2010, p. 147) são compostos por artigos científicos (44\%), teses e dissertações (30\%), documentos resultantes de comunicações em congressos e conferências (12\%) e outros tipos (14\%). Nesse contexto, verificou-se que no Brasil a situação não difere muito do cenário português, já que os artigos de periódico $(15,89 \%)$ representam a maioria dos documentos armazenados, seguidos pelos capítulos de livros $(14,02 \%)$, teses e dissertações $(13,08 \%)$, trabalhos publicados em anais de eventos (12,15\%), livros na íntegra (10,28\%), monografias/trabalhos de conclusão de curso (6,54\%), Preprints (artigos que ainda não foram publicados oficialmente) (6,54\%), vídeos $(5,61 \%)$, músicas $(5,61 \%)$, relatórios técnicos $(4,67 \%)$, imagens $(4,67 \%)$, patentes $(0,93 \%)$. Com esse resultado percebe-se a importância dos artigos de periódico como um dos meios de comunicação mais utilizados pela comunidade científica.

No que se refere às estatísticas de acesso e uso dos conteúdos, nota-se que esta importante ferramenta de acompanhamento e avaliação não vem sendo amplamente utilizada nos repositórios institucionais pesquisados, pois apenas 11 repositórios institucionais possuem esse recurso, enquanto que as outras 8 IES afirmam que seus repositórios não registram nenhum tipo de dado estatístico. As estatísticas são uma poderosa estratégia de marketing que as instituições podem utilizar para ampliarem o povoamento do repositório.

Divulgar, sistematicamente, estatísticas de acesso e download dos trabalhos depositados, como uma espécie de propaganda dos benefícios do repositório para os autores, com a expectativa de que, conhecendo os benefícios, pesquisadores se 
sentirão motivados a manter seus trabalhos depositados e, quiçá, passarão a realizar o autodepósito propriamente dito. (SAYÃO et al., 2009, p. 180).

Na construção e implantação de um repositório institucional existem questões que dificultam o perfeito funcionamento do mesmo (gráfico 4). A obtenção de recursos financeiros não foi percebida por nenhuma instituição como dificuldade. É importante ressaltar que nessa pergunta duas IES afirmaram não ter enfrentado nenhuma barreira para a implantação de seus repositórios. Por outro lado, percebe-se que a maior dificuldade enfrentada pelas equipes que gerenciam os repositórios é a falta de recursos humanos capacitados, o fator que talvez possa ser explicado pelo fato de que a temática dos repositórios institucionais é recente no universo acadêmico e por esse motivo, pouco conhecida.

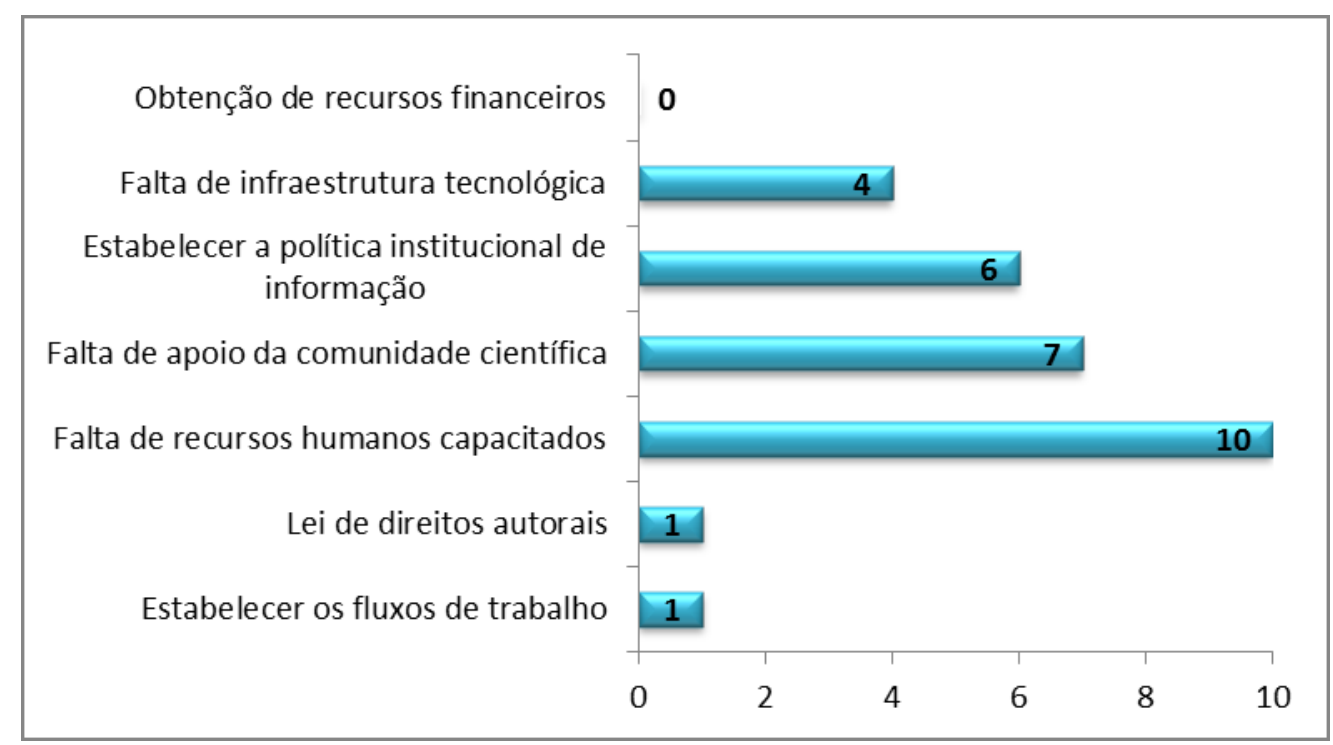

Gráfico 5: Dificuldades encontradas para a implantação do RI

\subsection{Apresentação e discussão dos dados obtidos com a observação direta dos sites}

No desenvolvimento da terceira etapa adotou-se como técnica de coleta de dados a observação direta dos sites institucionais das 50 (cinqüenta) IES que não responderam ao questionário eletrônico. Nessa etapa foram identificados 15 repositórios institucionais. A técnica de observação dos sites não permitiu que fossem identificadas informações que foram obtidas com o questionário, como por exemplo, o ano de implantação, se possuem ou não uma política de informação, entre outros fatores que são de extrema relevância para o mapeamento da pesquisa. 


\section{CONSIDERAÇÕES FINAIS}

O processo de comunicação científica tem sido significativamente impactado pela publicação eletrônica. Nesse cenário de transição, surgem discussões sobre o contexto das iniciativas de acesso livre à informação científica e das questões que englobam a implantação de repositórios. O diferencial dos repositórios institucionais consiste na capacidade que estes têm de armazenar e disseminar informações para que a sociedade possa ter acesso livre ao conhecimento científico, que antes estava restrito a poucos, questão que pode ser confirmada com o resultado da presente pesquisa, na qual a disseminação da produção científica da instituição foi apontada por todas as 19 instituições que afirmaram possuir RI, como o principal fator para a sua implantação.

As universidades públicas brasileiras precisam tomar conhecimento das questões que envolvem a implantação e o potencial que os repositórios institucionais possuem para ampliar a visibilidade das pesquisas produzidas no meio acadêmico. A principal dificuldade encontrada para a implantação dos RIs, destacada nesse trabalho, explicita a falta de recursos humanos capacitados nas IES públicas do país para trabalharem na construção e no gerenciamento de repositórios. Essa situação mostra que é importante que as IES que pretendem implantar seus RIs promovam treinamentos, com o objetivo de informar bibliotecários, analista de sistemas, professores/pesquisadores universitários e assistentes administrativos para que possam realizar o auto-arquivamento. Porém a inserção desses documentos será controlada por bibliotecários, responsáveis pela revisão dos metadados utilizados para catalogação dos documentos armazenados.

A falta de apoio da comunidade científica é outro fator que dificulta a implantação dos repositórios, porém esse problema pode ser explicado pelo fato de que a temática dos repositórios institucionais é recente no ambiente acadêmico e por esse motivo, pouco conhecida, fazendo com que pesquisadores não deem credibilidade às publicações eletrônicas, que muitas vezes não passam pela avaliação dos pares, diferente dos artigos publicados em periódicos científicos. Por isso é importante que a determinação da política institucional de informação, que irá nortear a implantação e o funcionamento do repositório institucional, seja elaborada por uma equipe multidisciplinar, incluindo bibliotecários, pesquisadores, analistas de sistemas e pessoal envolvido com a política universitária. Essa multidisciplinaridade implicará na adoção de políticas de depósito que facilitem a disseminação da informação científica, mas que ao mesmo tempo garantam a qualidade dos conteúdos depositados, o que irá melhorar a aceitação dos repositórios pela comunidade acadêmica. 
Com o estudo foi possível perceber que há poucas iniciativas de construção de RIs pelas IES públicas do país, pois apenas 34 (trinta e quatro) das 102 (cento e duas) IES pesquisadas possuem essa importante ferramenta de gestão do conhecimento científico. Espera-se que o Projeto de Lei do Senado 387/2011 que está tramitando no senado seja aprovado, pois esse fato implicará em uma considerável ampliação das iniciativas de RIs pelas universidades públicas do país. É imprescindível que os repositórios sejam vistos como uma conexão entre a ciência e a sociedade. 


\section{REFERÊNCIAS}

ARAÚJO, Eliany Alvarenga; DIAS, Guilherme Ataíde. A atuação profissional do bibliotecário no contexto da sociedade da informação: os novos espaços de informação. In: OLIVEIRA, Marlene (Org.). Ciência da Informação e Biblioteconomia: novos conteúdos e espaços de atuação. 2. ed. Belo Horizonte: Ed. UFMG, 2011. p. 109-120.

BRASIL. Projeto de Lei do Senado $n^{\circ}$ 387, de 05 de julho de 2011. Portal Atividade Legislativa. Disponível em:

$<$ http://www.senado.gov.br/atividade/materia/detalhes.asp?p_cod_mate=101006 $>$. Acesso em: 04 out. 2011.

COSTA, Sely. Filosofia aberta, modelos de negócios e agências de fomento: elementos essenciais a uma discussão sobre o acesso aberto à informação científica. Ciência da Informação, Brasília, v. 35, n. 2, p. 39-50, maio/ago. 2006. Disponível em: $<$ http://www.scielo.br/pdf/ci/v35n2/a05v35n2.pdf $>$. Acesso em: 04 jul. 2011.

CUENCA, Angela Maria Belloni; TANAKA, Ana Cristina d'Andretta. Influência da internet na comunidade acadêmico-científica da área de saúde pública. Rev. Saúde Pública, São Paulo, v. 39, n. 5, out. 2005 . Disponível em: $<$ http://www.scielo.br/scielo.php?script $=$ sci arttext\&pid $=$ S0034-

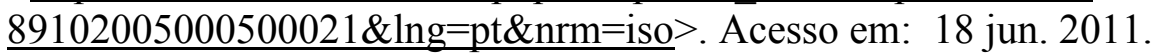

GOMES, Maria João; ROSA, Flávia (Org.). Repositórios institucionais: democratizando o acesso ao conhecimento. Salvador: EDUFBA, 2010.

GOMES, Sandra Rebel; MENDONÇA, Marília Alvarenga Rocha; SOUZA, Clarice Muhlethaler de. Literatura cinzenta. In: CAMPELLO, Bernadete Santos; CENDÓN, Beatriz Valadares; KREMER, Jeanette Marguerite (Org.). Fontes de informação para pesquisadores e profissionais. Belo Horizonte: Ed. UFMG, 2007. p. 97-103.

IBICT. Manifesto brasileiro de apoio ao acesso livre à informação científica. Brasília: IBICT, 2005. Disponível em: < http://kuramoto.files.wordpress.com/2008/09/manifestosobre-o-acesso-livre-a-informacao-cientifica.pdf $>$. Acesso em: 29 maio 2011.

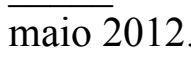

Diadorim. Disponível em: < http://diadorim.ibict.br/about/about.jsp\#>. Acesso em: 23

- DSpace Repositórios Digitais: perguntas frequentes. Disponível em: $<$ http://dspace.ibict.br/index.php?option=com_content\&task=view\&id=38\&Itemid=72> Acesso em: 23 maio 2012.

Repositórios brasileiros de acesso aberto serão lançados amanhã. 2010. Disponível em: $<$ http://www.ibict.br/noticia.php?id=732> . Acesso em:10 set. 2011.

LEITE, Fernando César Lima. Como gerenciar e ampliar a visibilidade da informação científica brasileira: repositórios institucionais de acesso aberto. Brasília,DF: IBICT, 2009. 
MEADOWS, A. J. A comunicação científica. Brasília, DF: Briquet de Lemos, 1999.

MUELLER, Suzana Pinheiro Machado. O periódico científico. In: CAMPELLO, Bernadete Santos; CENDÓN, Beatriz Valadares; KREMER, Jeannette Marguerite. (Org.) Fontes de informação para pesquisadores e profissionais. Belo Horizonte: Editora UFMG, 2007. p. 7395.

A comunicação científica e o movimento de acesso livre ao conhecimento. Ciência da Informação, Brasília, v. 35, n. 2, p. 27-38, maio/ago. 2006. Disponível em:

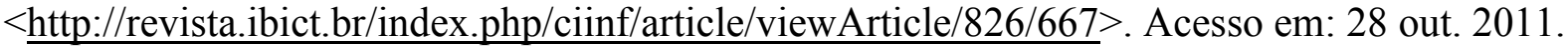

SAYÃO, Luis Fernando et al. (Org.). Implantação e gestão de repositórios institucionais: políticas, memória, livre acesso e preservação. Salvador: EDUFBA, 2009.

SILVA, Fernando Ferraz. A implantação de repositório institucional na academia de polícia militar do estado de Goiás. REBESP, Goiânia, v.1, n. 1, p. 5-15, jul./dez. 2008. Disponível

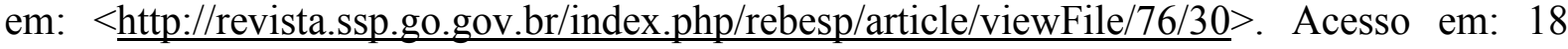
jun. 2011.

TARGINO, Maria das Graças. Comunicação Científica: uma revisão de seus elementos básicos. Informação \& Sociedade: estudos, João Pessoa, v. 10, n. 30, jan. 2000. Disponível em: $<$ http://www.ies.ufpb.br/ojs2/index.php/ies/article/view/326/248 $>$. Acesso em: 08 ago. 2011

TOMAÉL, Maria Inês (Org.). Fontes de informação na Internet. Londrina: EDUEL, 2008.

UNESCO. Relatório UNESCO sobre ciência 2010: o atual status da ciência em torno do mundo. Disponível em: <http://unesdoc.unesco.org/images/0018/001898/189883por.pdf $>$. Acesso em: 05 out. 2011 